\title{
Effects of cigarette smoke condensate on pneumococcal biofilm formation and
} pneumolysin

\author{
N. Daphney Mutepe*,\#, Riana Cockeran*,\#, Helen C. Steel*,\#, Annette J. Theron*,\#, \\ Tim J. Mitchell ${ }^{\mp}$, Charles Feldman ${ }^{+, \S}$ and Ronald Anderson*,\#
}

ABSTRACT: Although the well-recognised predisposition of cigarette smokers to the development of severe pneumococcal disease may be attributable to impairment of local host defences, less is known about the direct effects of smoke exposure on airway pathogens, or their virulence factors. In the current study, we have investigated the effects of cigarette smoke condensate (CSC) on biofilm formation by Streptococcus pneumoniae, and on the pore-forming activity of its major toxin, pneumolysin.

Biofilm formation following exposure of the pneumococcus to CSC $\left(20-160 \mu \mathrm{g} \cdot \mathrm{mL}^{-1}\right) \mathrm{was}$ measured using a crystal violet-based spectrophotometric procedure, while the pore-forming activity of recombinant pneumolysin was determined by a fura-2/acetoxymethyl ester-based spectrofluorimetric procedure to monitor the uptake of extracellular $\mathrm{Ca}^{2+}$ by isolated human neutrophils.

Exposure of the pneumococcus or pneumolysin to CSC resulted in significant dose-related augmentation of biofilm formation $\left(p \leqslant 0.05\right.$ at 80 and $\left.160 \mu \mathrm{g} \cdot \mathrm{mL}^{-1}\right)$ and substantial attenuation of the pore-forming interactions of pneumolysin, respectively.

Augmentation of biofilm formation and inactivation of pneumolysin as a consequence of smoking are likely to favour microbial colonisation and persistence, both being essential precursors of pneumococcal disease.

\section{KEYWORDS: Cigarette smoking, pneumococcus, severe pneumococcal disease}

$\mathbf{T}$ he organism Streptococcus pneumoniae is a major cause of morbidity and mortality worldwide. It commonly causes otitis media, meningitis and pneumonia, with the young and the elderly being particularly vulnerable, while in those infected with the HIV, all age groups are affected. Notwithstanding the threats posed by emerging antibiotic resistance, a significant percentage of patients with severe pneumococcal disease who receive appropriate antimicrobial chemotherapy still die [1]. Importantly, cigarette smoking is the strongest independent risk factor for invasive pneumococcal pneumonia, affecting the immunocompetent non-elderly, and is responsible for onehalf of the disease burden, apparently by promoting colonisation, a prerequisite for invasive disease [2].

Although the exact causes of the predisposing effect of the smoking habit on development of severe pneumococcal disease are incompletely understood, smoke-mediated impairment of airway host defences has been implicated. However, less is known about the direct effects of cigarette smoke on the pneumococcus. In the current study, we have investigated the effects of exposure to cigarette smoke condensate on biofilm formation by the pneumococcus, as well as on the bioactivity of its pore-forming, pro-inflammatory toxin, pneumolysin. Biofilm is a self-generated polymer matrix that insulates the pneumococcus and other microbial pathogens from host defences and antibiotics, promoting bacterial persistence [3]. Conversely, pneumolysin, considered by many to be one of the most important virulence factors of the pneumococcus, initiates, via its interactions with airway epithelial cells, an early inflammatory response primarily involving neutrophils, which controls colonisation [4].

\section{MATERIALS AND METHODS \\ Bacterial strains}

An antibiotic-sensitive, clinical isolate of $S$. pneumoniae, strain 172 (serotype 23F, multilocus sequence type (MLST) 81), was kindly provided by the National Institute of Communicable Diseases (NICD), Johannesburg, South Africa.

\section{AFFLLIATIONS}

${ }^{*}$ Medical Research Council (MRC) Unit for Inflammation and Immunity, Dept of Immunology, Faculty of Health Sciences, University of Pretoria,

${ }^{\#}$ Tshwane Academic Division of the National Health Laboratory Service, Pretoria,

+Division of Pulmonology, Dept of Internal Medicine, Charlotte Maxeke Johannesburg Academic Hospital, and

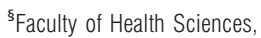
University of the Witwatersrand, Johannesburg, South Africa.

"Institute of Infection, Immunity and Inflammation, University of Glasgow, Glasgow, UK

CORRESPONDENCE

R. Cockeran

Dept of Immunology

Private Bag x323

Pretoria 0001

South Africa

E-mail: riana.cockeran@up.ac.za

Received:

Dec 052011

Accepted after revision:

May 062012

First published online:

June 272012

European Respiratory Journa

Print ISSN 0903-1936

Online ISSN 1399-3003 
The strain was grown overnight to the mid-logarithmic phase, at $37^{\circ} \mathrm{C}$ in an atmosphere of $5 \% \mathrm{CO}_{2}$ in tryptic soy broth (TSB; Merck, Darmstadt, Germany) followed by turbidometric numerical standardisation of the culture, representing $6.14 \times 10^{6}$ colony-forming units $(\mathrm{cfu}) \cdot \mathrm{mL}^{-1}$, before treatment with or without cigarette smoke condensate (CSC). A limited number of experiments was also performed with strain 3328 (serotype 14, MLST ST230), an ermB-expressing macrolide-resistant strain of the pneumococcus.

\section{Chemicals and reagents}

All chemicals and reagents, unless otherwise indicated, were obtained from the Sigma Chemical Co. (St Louis, MO, USA).

\section{Cigarette smoke condensate}

CSC was purchased from Murty Pharmaceuticals (Lexington, KY, USA) and used at final concentrations of 20, 40, 80 and $160 \mu \mathrm{g} \cdot \mathrm{mL}^{-1}$. Solvent controls (dimethyl sulfoxide (DMSO)) were included in all experiments. The total amount of condensate generated during the combustion of one cigarette is $26.3 \mathrm{mg}$ [5]; therefore the concentrations of CSC used in this study are relevant in the context of the smoking habit.

\section{Effects of CSC on the growth of S. pneumoniae}

S. pneumoniae was exposed to CSC $\left(20-160 \mu \mathrm{g} \cdot \mathrm{mL}^{-1}\right)$ or the solvent control for $16 \mathrm{~h}$ at $37^{\circ} \mathrm{C}$, in an atmosphere of $5 \% \mathrm{CO}_{2}$. The growth of the planktonic bacteria was determined by standard viable cell count procedures.

\section{Effects of CSC on biofilm formation by S. pneumoniae}

The bacteria in growth medium were exposed to CSC (20$160 \mu \mathrm{g} \cdot \mathrm{mL}^{-1}$ ) or the solvent control for $16 \mathrm{~h}$ at $37^{\circ} \mathrm{C}, 5 \% \mathrm{CO}_{2}$, in a six-well tissue culture plate to facilitate adherence and biofilm formation. Following incubation, the nonadherent bacteria and medium were removed, and the wells washed three times with PBS (0.15 M; Beckton Dickinson and Co., Sparks, MD, USA). Following the removal of all the unbound bacteria, the biofilm was stained with $0.1 \%$ crystal violet, the excess dye was removed and the wells washed five times with PBS. The crystal violet was released from the adherent bacteria by the addition of $96 \%$ ethanol and the amount of biofilm formed determined spectrophotometrically at a wavelength of $570 \mathrm{~nm}$ using the PowerwaveX (Bio-Tec Instruments Inc., Winooski, VT, USA) plate reader.

\section{Neutrophils}

The study was approved by the Research Ethics Committee, Faculty of Health Sciences, University of Pretoria, Pretoria, South Africa (protocol number S1/2011).

Purified neutrophils were prepared from heparinised $\left(5 \mathrm{U} \cdot \mathrm{mL}^{-1}\right.$ preservative-free heparin) venous blood from healthy adult volunteers. These were routinely of high purity $(>90 \%)$ and viability (>95\%) [6].

\section{Spectrofluorimetric measurement of cytosolic $\mathrm{Ca}^{2+}$}

For these experiments, recombinant pneumolysin $\left(20 \mu \mathrm{g} \cdot \mathrm{mL}^{-1}\right)$ [6] was treated with either 20 or $40 \mu \mathrm{g} \cdot \mathrm{mL}^{-1} \mathrm{CSC}$ or DMSO control for a period of $10 \mathrm{~min}$ at room temperature. The effect of CSC on the pore-forming activity of pneumolysin was then assessed according to the magnitude of uptake of extracellular $\mathrm{Ca}^{2+}$ by neutrophils, using the fluorescent $\mathrm{Ca}^{2+}$-sensitive dye fura-2/acetoxymethyl ester (AM) [6]. Neutrophils $\left(1 \times 10^{7}\right.$ per $\mathrm{mL})$ were pre-loaded with fura-2/AM ( $2 \mu \mathrm{M}$, final) for $30 \mathrm{~min}$ at $37^{\circ} \mathrm{C}$ in PBS, washed twice and resuspended in indicator-free Hanks' balanced salt solution (HBSS; Highveld Biological, Johannesburg, South Africa). The fura-2/AM-loaded neutrophils $\left(2 \times 10^{6}\right.$ per $\left.\mathrm{mL}\right)$ were pre-incubated for $10 \mathrm{~min}$ at $37^{\circ} \mathrm{C}$ after which they were transferred to disposable cuvettes, which were maintained at $37^{\circ} \mathrm{C}$ in a Hitachi $65010 \mathrm{~S}$ Fluorescence Spectrophotometer (Hitachi High-Technologies Corporation, Tokyo, Japan) with excitation and emission wavelengths set at 340 and $500 \mathrm{~nm}$, respectively. After a stable baseline was obtained ( $\sim 1 \mathrm{~min}$ ), the neutrophils were exposed to $3 \mu \mathrm{L} \mathrm{CSC}$ treated or -untreated (control) pneumolysin and alterations in cytosolic $\mathrm{Ca}^{2+}$ concentrations were monitored over a 7-min time course. The final volume in each cuvette was $3 \mathrm{~mL}$, containing a total of $6 \times 10^{6}$ neutrophils, and the final concentrations of pneumolysin and CSC were $20 \mathrm{ng} \cdot \mathrm{mL}^{-1}$ and 20 or $40 \mathrm{ng} \cdot \mathrm{mL}^{-1}$, respectively. At these concentrations (20 and $40 \mathrm{ng} \cdot \mathrm{mL}^{-1}$ ), CSC has no effects on neutrophils (data not shown).

\section{Statistical analysis}

Five and six separate experiments were performed for measurement of the effects of CSC on growth and biofilm formation (strain 172) and for pneumolysin bioactivity respectively, while three experiments were performed using strain 3328 of the pneumococcus. The results are expressed as median values with $95 \%$ confidence limits or as fura-2/AM fluorescence traces for the biofilm and pneumolysin experiments respectively. Statistical significance was calculated by the Mann-Whitney Utest (two-tailed); $\mathrm{p}$-values of $\leqslant 0.05$ were considered significant.

\section{RESULTS}

Effects of CSC on the growth and viability of S. pneumoniae The effects of CSC $\left(20-160 \mu \mathrm{g} \cdot \mathrm{mL}^{-1}\right)$ on the growth of planktonic S. pneumoniae strain 172 are shown in figure 1a. The condensate did not significantly affect the viability of strain 172, as was the case with strain 3328 (data not shown).

\section{Effects of CSC on biofilm formation by S. pneumoniae}

The effects of CSC $\left(20-160 \mu \mathrm{g} \cdot \mathrm{mL}^{-1}\right)$ on biofilm formation by strain 172 of S. pneumoniae are shown in figure 1b. Exposure of the pneumococcus to CSC resulted in a dose-dependent increase in biofilm formation, which reached statistical significance at 80 and $160 \mu \mathrm{g} \cdot \mathrm{mL}^{-1}$. In the case of strain 3328 , exposure to CSC at 80 and $160 \mu \mathrm{g} \cdot \mathrm{mL}^{-1}$ caused a significant $(\mathrm{p}<0.001)$ increase in biofilm formation, the median optical density (OD) values (upper 95\% confidence limit) for the control, and 80 and $160 \mu \mathrm{g} \cdot \mathrm{mL}^{-1}$ CSC-treated systems being 0.074 (0.0778), 0.092 (0.0982) and $0.117(0.1595)$, respectively.

\section{Effects of CSC on the bioactivity of pneumolysin}

The effects of exposure of neutrophils to untreated and CSCtreated pneumolysin on the pore-forming activity of the toxin measured according to the influx of extracellular $\mathrm{Ca}^{2+}$ are shown in figure 2. Exposure of neutrophils to control pneumolysin at $20 \mathrm{ng} \cdot \mathrm{mL}^{-1}$ was followed by a lag phase of $\sim 20 \mathrm{~s}$ and by an abrupt increase in fluorescence intensity thereafter due to the influx of extracellular $\mathrm{Ca}^{2+}$, which reached a plateau after $\sim 3$ min. Addition of CSC-treated pneumolysin to neutrophils was associated with a prolongation of the lag phase (1.5$2.5 \mathrm{~min})$, followed by a significant $(\mathrm{p}<0.0028-<0.0002)$ 

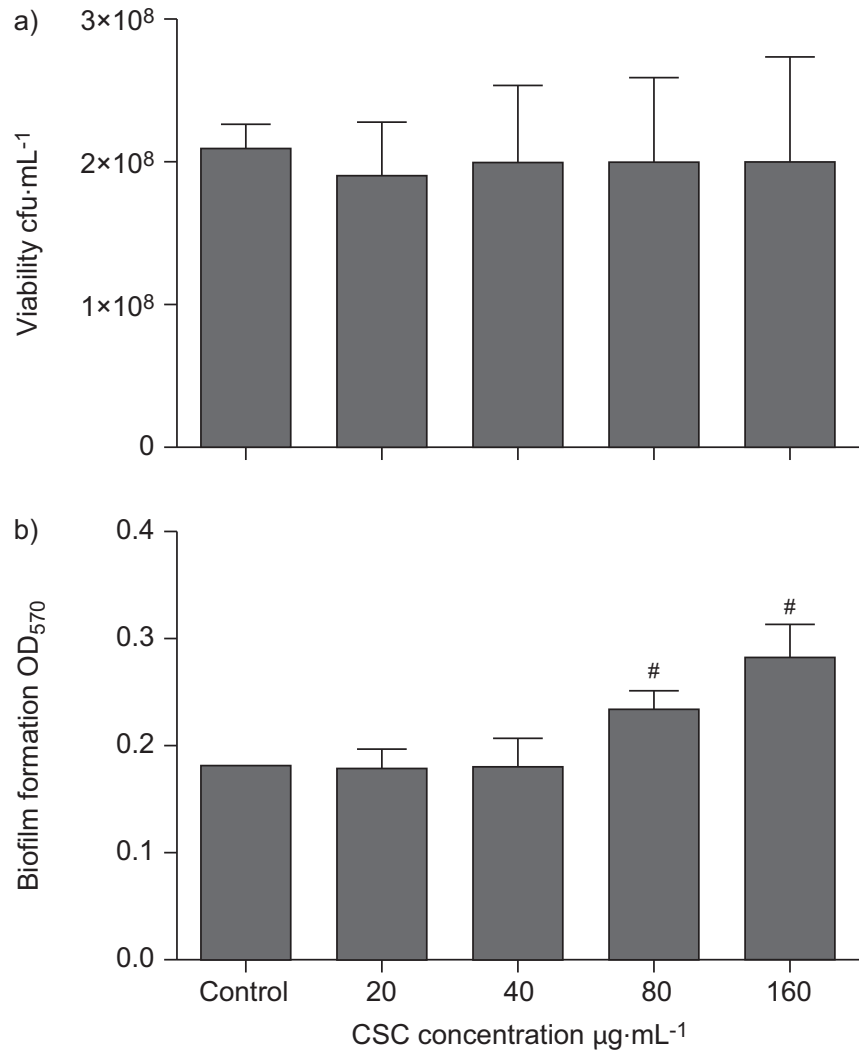

FIGURE 1. Effects of exposure of Streptococcus pneumoniae to cigarette smoke condensate (CSC) on a) viability, measured as colony-forming units (cfu) per $\mathrm{mL}$ and b) biofilm formation, measured spectrophotometrically by crystal violet staining at a wavelength of $570 \mathrm{~nm}$. The results are presented as the median values and $95 \%$ confidence limits of five different experiments, with three replicates for each system in each experiment. $\mathrm{OD}_{570}$ : absorbance at $570 \mathrm{~nm}$. ${ }^{*}: \mathrm{p} \leqslant 0.05$ when compared with the solvent control.

attenuation of influx of cytosolic $\mathrm{Ca}^{2+}$, compatible with loss of pore-forming activity.

\section{DISCUSSION}

The results of this study clearly demonstrate that exposure of the pneumococcus to CSC for $16 \mathrm{~h}$, at concentrations that are representative of the smoking habit, results not only in the augmentation of biofilm formation in the absence of detectable levels of growth, but also substantial inactivation of the poreforming, pro-inflammatory activity of its major toxin, pneumolysin. CSC, possibly by acting as a stressor, may activate quorum-sensing mechanisms, which, in turn, initiate biofilm formation, enabling the pneumococcus to enter a quiescent, persistent phase from which it can re-emerge when host defences are transiently compromised [4]. We cannot exclude the possibility that prolonged exposure to CSC at higher concentrations than those used in the current study may affect the growth of the pneumococcus.

We do concede, however, that brief exposure of the pneumococcus to CSC in vitro is not entirely representative of exposure to inhaled cigarette smoke in the airways. Nonetheless, several other groups have recently reported on the effects of cigarette smoke exposure on biofilm formation by various microbial

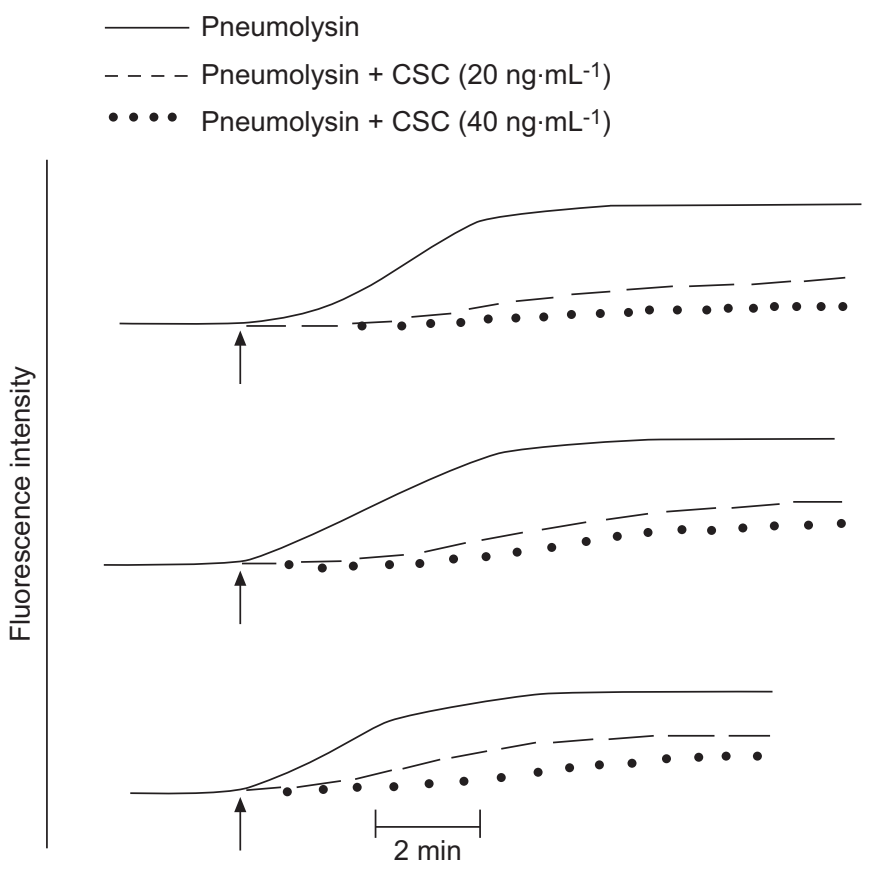

FIGURE 2. Fura-2/acetoxymethyl ester fluorescence responses of neutrophils following exposure to cigarette smoke condensate (CSC; final concentration of 20 or $40 \mathrm{ng} \cdot \mathrm{mL}^{-1}$ )-treated or -untreated pneumolysin (at a fixed, final concentration of $20 \mathrm{ng} \cdot \mathrm{mL}^{-1}$ ). Pneumolysin (with or without CSC pre-treatment) was added as indicated by vertical arrows after a stable baseline was achieved ( $\sim 1 \mathrm{~min})$. Data from three experiments, using cells from three different donors are shown. A total of six different experiments, using neutrophils from six different donors were performed, all showing comparable results. $p<0.0028$ to $<0.0002$ for comparison of the areas under the curve for the control system with those of the CSC-treated systems for all six experiments.

pathogens. BABONI et al. [7] reported that exposure of both Streptococcus mutans and Candida albicans to CSC increased the adherence of these oral pathogens to orthodontic material in the setting of increased biofilm formation [7], while BAGAITKAR et al. [8] also observed increased biofilm formation following exposure of another oral pathogen, Porphyromonas gingivalis, to CSC. Even more recently, GolDSTEIN-DARUACH et al. [9] reported that exposure of a range of bacterial pathogens, isolated from the sinonasal cavities of smokers, to smoke generated by combustion of five reference cigarettes resulted in activation of biofilm formation [9].

To our knowledge, the effects of cigarette smoke on the bioactivity of the pneumococcal toxin pneumolysin have not been described previously. When released at high concentrations during severe pneumococcal disease, pneumolysin, as a consequence of its cytolytic and pro-inflammatory activities, causes acute lung injury following extracellular dissemination of the pneumococcus [1]. However, during the early stages of colonisation when numbers of the pneumococci are low, pneumolysin, via its pore-forming interactions with airway epithelial cells, promotes production of interleukin- 8 and early influx of neutrophils that contribute to the early control of colonisation $[4,10]$. In the current study, exposure to very low concentrations of CSC resulted in attenuation of the pore-forming activity of pneumolysin, probably by oxidative inactivation, which is likely to favour colonisation. 
In conclusion, these effects of cigarette smoke on both biofilm formation and the bioactivity of pneumolysin may promote both colonisation and persistence, important precursors of invasive pneumococcal disease.

\section{SUPPORT STATEMENT}

C. Feldman and R. Cockeran are supported by the National Research Foundation of South Africa.

\section{STATEMENT OF INTEREST}

None declared.

\section{REFERENCES}

1 Feldman C, Anderson R. Bacteraemic pneumococcal pneumonia: current therapeutic options. Drugs 2011; 22: 131-153.

2 Nuorti JP, Butler JC, Farley MM, et al. Cigarette smoking and invasive pneumococcal disease. N Engl J Med 2000; 342: 681-689.

3 Oggioni MR, Trapetti C, Kadiaglu A, et al. Switch from planktonic to sessile life: a major event in pneumococcal pathogenesis. Mol Microbiol 2006; 61: 1196-1210.
4 Ratner AJ, Hippe KR, Aguilar JL, et al. Epithelial cells are sensitive detectors of bacterial pore-forming toxins. J Biol Chem 2006; 281: 12994-12998.

5 Davies RF, Day TD. A study of the comparative carcinogenicity of cigarette and cigar smoke condensate on mouse skin. Br J Cancer 1969; 23: 363-368.

6 Anderson R, Steel HC, Cockeran R, et al. Clarithromycin alone and in combination with ceftriaxone inhibits the production of pneumolysin by both macrolide-susceptable and macrolide-resistant strains of Streptococcus pneumoniae. J Antimicrob Chemother 2007; 59: 224-229.

7 Baboni FB, Guariza Filho O, Moreno AN, et al. Influence of cigarette smoke condensate on cariogenic and candidal biofilm formation on orthodontic materials. Am J Orthod Dentofacial Orthop 2010; 138: 427-434.

8 Bagaitkar J, Demuth DR, Daep CA, et al. Tobacco upregulates $P$. gingivalis fimbrial proteins which induce TLR2 hyposensitivity. PLoS One 2010; 5: e9323.

9 Goldstein-Daruech N, Cope EK, Zhao KQ, et al. Tobacco smoke mediated induction of sinonasal microbial biofilms. PLoS One 2011; 6: e15700.

10 van Rossum AMC, Lysenko ES, Weiser JN. Host and bacterial factors contributing to the clearance of colonization by Streptococcus pneumoniae in a murine model. Infect Immun 2005; 73: 7718-7726. 